\title{
Efficacy and safety of azoximer bromide (Polyoxidonium) in children aged from 1 to 12 years with ARI: The results of a multicenter prospective, randomized, double-blind, placebo-controlled, parallel-group study
}

\author{
Garashchenko TI" ${ }^{*}$, Karneeva OV², Tarasova GT ${ }^{3 \#}, \mathrm{Kim} \mathrm{IA}^{3}$ and Hanferian RA ${ }^{4,5}$ \\ ${ }^{1}$ Federal State Budgetary Institution, The National Medical Research Center for Otorhinolaryngology for the Federal Medico-Biological Agency of Russia, Russia \\ ${ }^{2}$ Science and Education of the Federal State Budgetary Institution, The National Medical Research Center for Otorhinolaryngology for the Federal Medico- \\ Biological Agency of Russia, Russia \\ ${ }^{3}$ Research Department of the Federal State Budgetary Institution, The National Medical Research Center for Otorhinolaryngology for the Federal Medico-Biological \\ Agency of Russia, Russia \\ ${ }^{4}$ Department of Immunology and Allergology of the Federal State Autonomous Educational Institution of Higher Education, Peoples' Friendship University of \\ Russia, Russia \\ ${ }^{5}$ Federal State Budgetary Institution, The National Medical Research Center for Otorhinolaryngology for the Federal Medico-Biological Agency of Russia, Russia
}

\begin{abstract}
Purpose: To confirm the superiority of the therapeutic effect of topical use of azoximer bromide (Polyoxidonium) in comparison with placebo in children from 1 to 12 years of age with ARVI.

Patients and methods: The study included 155 children: the main group consisted of 76 children with azoximer bromide, the comparison group consisted of 79 children with placebo included in the complex treatment. The study evaluated the dynamics of intoxication symptoms, symptoms of inflammation of the nasal mucous membrane, the total sum of all symptoms in points to 3,5 and 8 days of treatment, the duration of the fever period as criteria for evaluation the effectiveness of therapy.

Results: According to the study results, the efficacy of azoximer bromide use in the complex therapy of children from 1 to 12 years with ARVI can be stated. Inclusion of azoximer bromide in the complex treatment of ARVI in children as compared to placebo allows to control better the symptoms of intoxication, to reduce the severity of symptoms of "nasal discharge" and "nasal congestion" by the 5 th day of therapy, to increase twice the number of patients with no symptoms of "Nasal discharge" by the 3rd and 5 th days of therapy, to reduce the severity of infectious and inflammatory process. The number of adverse events on the background of azoximer bromide use is not statically significantly different from the number of adverse events on the placebo use background, which indicates the safety of azoximer bromide.
\end{abstract}

Conclusion: Topical use of azoximer bromide in complex treatment of ARVI in children from 1 to 12 years is clinically effective and safe.

Abbreviations: ARVI: Acute Respiratory Viral Infection; UA: Upper Airways; NET: Neutrophil Extracellular Traps.

\section{Introduction}

Acute respiratory viral infections (ARVI) remain one of the most relevant problems due to the high specific weight in the infectious pathology, the risk of severe complications. Children under 14 are significantly more likely to have ARVI than adults [1].

Symptoms of inflammation and intoxication of ARVI significantly impair the child quality of life and his parents during the illness. In connection with the above mentioned, it is relevant to search for methods to facilitate the course of ARVI and reduce the complications probability.

Azoximer bromide (Polyoxidonium ${ }^{\circledR}$ ), which has a complex action is of interest: immunomodulatory, detoxifying and anti-inflammatory effects. An important mechanism among the effects of azoximer bromide is the activation of non-specific factors of mucous membrane protection. The main mechanism of the immunomodulatory action of bromide azoximer is direct action on phagocytic cells and natural killers, as well as stimulation of antibody formation and interferon-alpha and

${ }^{\star}$ Correspondence to: TTatyana Ilyinichna Garashchenko, Federal State Budgetary Institution, The National Medical Research Center for Otorhinolaryngology for the Federal Medico-Biological Agency of Russia, Russia, Tel: +79162360009 , +79169040100; E-mail: 9040100@mail.ru

Galina Dmitrievna Tarasova, Research Department of the Federal State Budgetary Institution, The National Medical Research Center for Otorhinolaryngology for the Federal Medico-Biological Agency of Russia, Russia, Tel: Phone +79166083431; E-mail: gtarasova@yandex.ru

Key words: children, ARVI, azoximer bromide, polyoxidonium, clinical study

Received: May 17, 2020; Accepted: May 29, 2020; Published: June 04, 2020 
Garashchenko TI (2020) Efficacy and safety of azoximer bromide (Polyoxidonium) in children aged from 1 to 12 years with ARI: The results of a multicenter prospective, randomized, double-blind, placebo-controlled, parallel-group study

interferon-gamma synthesis. The studies show that azoximer bromide increases the phagocytic activity of macrophages and neutrophils $[2,3]$. In vitro study has shown that this drug is able to inhibit the formation of suicidal neutrophil extracellular traps (NET) [4]. Several studies have shown that the severity of rhinoviral infection and influenza, acute moderate otitis, acute and chronic rhinosinusitis, pneumonia and other infectious diseases is correlated with the level of NET formation $[2,5,6]$.

The anti-inflammatory action of azoximer bromide is realized by normalization of pro- and anti-inflammatory cytokines synthesis and also connected with suppression of NET formation. Detoxifying properties are explained by the peculiarity of the molecule structure - a large number of different active groups on its surface, which intensively bind soluble toxic substances and micro-particles circulating in blood [2].

The purpose of our study: to confirm the superiority of the therapeutic effect of topical use of azoximer bromide (Polyoxidonium ${ }^{\star}$ ) in comparison with placebo when used as part of complex therapy in children aged 1 to 12 years with ARVI.

\section{Patients and methods}

A multicenter prospective randomized double-blind placebocontrolled clinical trial of the efficacy and safety of the studied drug was performed in children aged 1 to 12 years with ARVI, not requiring admission to hospital. The study was conducted at 11 centers in Russia.

The study was fully performed in outpatient settings according scheme of study (Figure 1). Visits 0,1 and 2 were carried out by doctor's visit at home.

In total 4-5 visits were performed: Visit 0 (day -1 - screening), Visit 1 (day 1 - randomization), Visit 2 (day 3), Visit 3 (day 5 - phone call), Visit 4 (day $8 \pm 1$ ) and Visit 5 (day $12 \pm 1$ - phone call). Visit 0 and Visit 1 were matched in most cases.

In total 175 children were screened, 3 of them did not fulfill the inclusion criteria. 172 children were randomized, and 8 children dropped out due to serious protocol violations, adverse events in the background of therapy). A total of 164 people completed the study, but data from 155 children were accepted for the final analysis ( 9 were excluded from the analysis due to serious violations of protocol procedures during the study, which were identified during the data analysis).

Children were included in the study if the following inclusion criteria were met:

1. Patients of both genders from 1 to 12 years of age inclusive.

2. Diagnosis of ARVI according to the doctor's examination: axillary temperature $\geq 37^{\circ} \mathrm{C}$ at the time of examination and the total number of points of symptom severity $\geq 5$ points, of which at least 3 points - symptoms of ENT organs and UA (according to the "Symptoms evaluation scale", Table 1).

3. No more than 24 hours from the onset of ARVI symptoms.

4. Presence of the informed consent form signed by one of the parents/ adopters and the child (if the age $>10$ years).

\section{Study non-inclusion criteria}

1. suspected pneumonia, bacterial infection (including meningitis, sepsis, otitis media, rhinosinusitis, urinary tract infection, etc.) or the presence of a disease requiring the antibacterial drugs prescription from the first day of the disease.

2. Suspicion of the initial diseases manifestations that have in the debut similar to ARVI symptoms (other infectious diseases, influenza-like

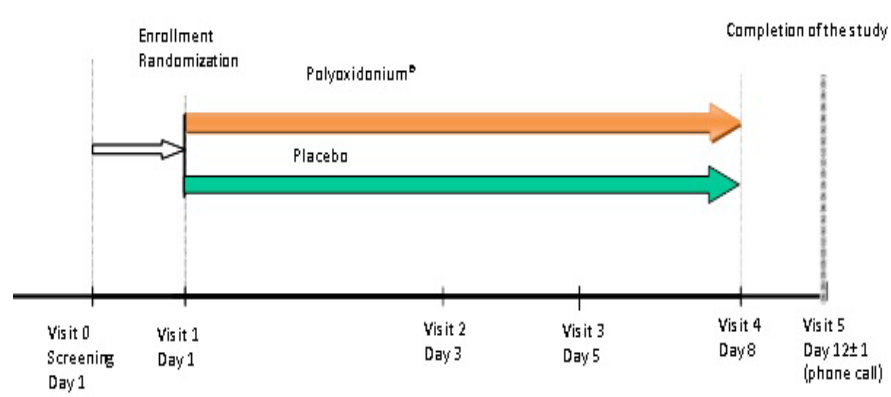

Figure 1. Scheme of the study

Table 1. Symptom assessment scale (to be filled in by parent/adopter himself).

\begin{tabular}{|c|c|c|c|c|}
\hline \multirow{2}{*}{$\begin{array}{l}\text { General symptoms of intoxication } \\
\text { Modified/decreased activity (or disturbed behavior) }\end{array}$} & \multicolumn{4}{|c|}{ Assessment } \\
\hline & $\begin{array}{c}\text { None } \\
(0 \text { points })\end{array}$ & $\begin{array}{c}\text { Mild } \\
\text { (1 point) }\end{array}$ & $\begin{array}{l}\text { Moderate } \\
\text { ( } 2 \text { points) }\end{array}$ & $\begin{array}{c}\text { Severe } \\
(3 \text { points })\end{array}$ \\
\hline Disturbed appetite or refusal to feed & $\begin{array}{c}\text { None } \\
(0 \text { points })\end{array}$ & $\begin{array}{l}\text { Mild } \\
\text { (1 point) }\end{array}$ & $\begin{array}{l}\text { Moderate } \\
\text { ( } 2 \text { points) }\end{array}$ & $\begin{array}{c}\text { Severe } \\
\text { (3 points) }\end{array}$ \\
\hline Painful (or different) appearance & $\begin{array}{c}\text { None } \\
(0 \text { points })\end{array}$ & $\begin{array}{l}\text { Mild } \\
\text { (1 point) }\end{array}$ & $\begin{array}{l}\text { Moderate } \\
\text { ( } 2 \text { points) }\end{array}$ & $\begin{array}{c}\text { Severe } \\
(3 \text { points })\end{array}$ \\
\hline Disturbed or altered sleep & $\begin{array}{c}\text { None } \\
(0 \text { points })\end{array}$ & $\begin{array}{c}\text { Mild } \\
\text { (1 point) }\end{array}$ & $\begin{array}{l}\text { Moderate } \\
\text { (2 points) }\end{array}$ & $\begin{array}{c}\text { Severe } \\
(3 \text { points })\end{array}$ \\
\hline \multicolumn{5}{|l|}{ Nasal symptoms } \\
\hline Nasal discharge & $\begin{array}{c}\text { None } \\
(0 \text { points })\end{array}$ & $\begin{array}{l}\text { Mild } \\
\text { (1 point) }\end{array}$ & $\begin{array}{l}\text { Moderate } \\
\text { ( } 2 \text { points) }\end{array}$ & $\begin{array}{c}\text { Severe } \\
(3 \text { points })\end{array}$ \\
\hline Nasal congestion/impaired nasal airflow & $\begin{array}{c}\text { None } \\
(0 \text { points })\end{array}$ & $\begin{array}{c}\text { Mild } \\
\text { (1 point) }\end{array}$ & $\begin{array}{l}\text { Moderate } \\
(2 \text { points })\end{array}$ & $\begin{array}{c}\text { Severe } \\
\text { (3 points) }\end{array}$ \\
\hline Sneeze & $\begin{array}{c}\text { None } \\
(0 \text { points })\end{array}$ & $\begin{array}{c}\text { Mild } \\
\text { (1 point) }\end{array}$ & $\begin{array}{l}\text { Moderate } \\
\text { (2 points) }\end{array}$ & $\begin{array}{c}\text { Severe } \\
(3 \text { points })\end{array}$ \\
\hline \multicolumn{5}{|l|}{ The throat and chest symptoms } \\
\hline Hoarseness & $\begin{array}{c}\text { None } \\
(0 \text { points })\end{array}$ & $\begin{array}{c}\text { Mild } \\
\text { (1 point) }\end{array}$ & $\begin{array}{l}\text { Moderate } \\
\text { ( } 2 \text { points) }\end{array}$ & $\begin{array}{c}\text { Severe } \\
(3 \text { points })\end{array}$ \\
\hline Sore throat & $\begin{array}{c}\text { None } \\
(0 \text { points })\end{array}$ & $\begin{array}{c}\text { Mild } \\
\text { (1 point) }\end{array}$ & $\begin{array}{l}\text { Moderate } \\
\text { ( } 2 \text { points) }\end{array}$ & $\begin{array}{c}\text { Severe } \\
\text { (3 points) }\end{array}$ \\
\hline Cough & $\begin{array}{c}\text { None } \\
(0 \text { points })\end{array}$ & $\begin{array}{l}\text { Mild } \\
\text { (1 point) }\end{array}$ & $\begin{array}{l}\text { Moderate } \\
\text { (2 points) }\end{array}$ & $\begin{array}{c}\text { Severe } \\
(3 \text { points })\end{array}$ \\
\hline
\end{tabular}


syndrome in the debut of systemic diseases of connective tissue and other pathology).

3. Influenza or streptococcal infection according to the rapid test results.

4. Clinical symptoms of severe ARVI requiring hospitalization (fever $\geq 40^{\circ} \mathrm{C}$, signs of airway obstruction, marked hemodynamic/ neurological disorders).

5. Presence in anamnesis or previously diagnosed primary and secondary immunodeficiency

6. Cancer

7. Acute infectious or non-infectious diseases (except for ARVI), as well as exacerbation or decompensation of chronic diseases (diabetes mellitus, cerebral spastic infantile paralysis, cystic fibrosis, primary ciliary dyskinesia, bronchopulmonary dysplasia, malformations of respiratory and ENT organs, etc.), affecting the ability of a patient to participate in clinical trial.

8. Sucrase-isomaltase deficiency, fructose intolerance, glucosegalactose malabsorption.

9. Allergy/hypersensitivity to any component of drugs used in treatment (including sensitivity to paracetamol, propacetamol hydrochloride (paracetamol prodrug)).

10. Taking the drugs specified in the part "Unauthorized concomitant treatment" 1 month before to inclusion in the study.

11. Patients whose parents/adopters, from the investigator's point of view, will not comply with observation requirements during the course of the study or will not follow the procedure for taking the studied drugs

12. Participation in other clinical drug studies for less than 3 months before the screening visit.

\section{Pregnancy}

14. Any other medical or social condition that, in the opinion of the study physician, prevents a child from participating in this study.

All patients included in the study on Visit 0-1 (Day -1,1) were randomized to two therapy groups at a ratio of 1:1 according to the randomization number. Patients in one group received the studied Polyoxidonium ${ }^{\oplus}$, nasal and sublingual spray, $6 \mathrm{mg} / \mathrm{ml}$ (NPO Petrovax Pharm, Russia), in another group - Placebo, nasal and sublingual spray, which did not differ in appearance from spray Polyoxidonium ${ }^{\star}$ (NPO Petrovax Pharm, Russia). The duration of the therapy was 7 days. The drug was used every day in a daily dose of $0.15 \mathrm{mg} / \mathrm{kg}$, children from 1 to 2 years of age took the drug sublingually, children over 2 years intranasal.

Paracetamol in age-dose was administered at body temperature of $38.5^{\circ} \mathrm{C}$ and above in patients, the drug was allowed to use no more than 3 days.

The following drugs for symptomatic treatment of ARVI could be prescribed in conjunction with the administration of the studied drug, according to the decision of the physician, to patients participating in this study: ascorbic acid, adrenomimetics (intranasally), expectorants, mucolytics (acetylcysteine), fenspiride.

The following criteria were used in the study as criteria for evaluation the effectiveness of therapy:
1. Dynamics of intoxication symptoms, nasal symptoms, symptoms, total sum of all symptoms in scores to day 3,5 and 8 of treatment (Table 1).

2. The duration of the fever period. The end of the fever period is considered to be the presence of axillary body temperature $\leq 36.9^{\circ} \mathrm{C}$ in two consecutive measurements (morning/evening/evening morning).

The safety of therapy was evaluated throughout the study, and the safety assessment took into account data from all patients who had taken at least one dose of the studied drug

\section{Statistical analysis}

Efficiency data were analyzed in a population of patients who had undergone all the study procedures and completed it according to the protocol.

Comparison of quantitative indicators meeting the conditions of normal distribution and dispersion test was carried out using the Student's test. The Mann-Whitney test was used to compare quantitative indicators that did not meet the conditions of normal distribution or dispersion test paired Student t-test was used to compare paired quantitative indicators that satisfy normal distribution conditions and dispersion test; Wilcoxon's test was used to compare paired quantitative indicators that do not satisfy normal distribution conditions or dispersion test. Comparative analysis of qualitative variables was carried out using $\chi^{2}$ method, if more than $20 \%$ of the expected frequencies were less than 5, the exact two-sided Fisher's test was used. Differences were considered statistically significant at $\mathrm{p}<0.05$.

\section{Results and discussion}

Data from 155 patients (Table 2) who underwent a protocol study were used to analyze the effectiveness of their therapy:

- the main group consisted of 76 patients who took Polyoxidonium ${ }^{\circledR}$;

- the comparison group included 79 placebo patients.

No statistically significant differences were found between the groups in terms of gender $\left(\mathrm{p}=0.126\right.$, Pearson's test $\left.\chi^{2}\right)$, age $(\mathrm{p}=0.342$, Mann-Whitney test) and patient distribution by age group $(\mathrm{p}=0.479$, Pearson's test $\chi^{2}$ ). The groups of patients receiving the studied drug and placebo patients did not have statistically significant differences in frequency of previous or concomitant diseases/surgeries $(\mathrm{p}=0.939$, Pearson's test $\left.\chi^{2}\right)$, allergy in history $(\mathrm{p}=0.064$, Fisher's exact test), concomitant drug frequency before the study $\left(\mathrm{p}=0.914\right.$, Pearson's test $\left.\chi^{2}\right)$.

\section{Dynamics of intoxication and fever symptoms}

There were no statistically significant differences in all "Symptom evaluation scale" indicators between the patient groups at baseline stage (screening)

Table 2. Characteristics of patient groups

\begin{tabular}{|l|c|c|}
\hline & $\begin{array}{c}\text { Main group } \\
\text { (Polyoxidonium (azoximer } \\
\text { bromide)) }\end{array}$ & $\begin{array}{c}\text { Comparison group } \\
\text { (placebo) }\end{array}$ \\
\hline Number of patients & 76 children & 79 children \\
\hline Gender & $33(\mathrm{f}) / 43(\mathrm{~m})$ & $41(\mathrm{f}) / 38(\mathrm{~m})$ \\
\hline Age, years (median) & 6 & 5 \\
\hline Age distribution & \multicolumn{2}{|l|}{} \\
\hline $1-2$ years & 11 children & 10 children \\
\hline 2-5 years & 21 children & 28 children \\
\hline $5-8$ years & 18 children & 22 children \\
\hline 8 -12 years & 26 children & 19 children \\
\hline
\end{tabular}


The average duration of the fever in the placebo group of $2.26 \pm$ 1.06 days exceeded the corresponding value of $2.04 \pm 1.33$ days in the azoximer bromide group (Polyoxidonium). The medians of the fever duration were 2.20 days and 1.92 days in the groups of patients treated with placebo and azoximer bromide (Polyoxidonium), respectively ( $p=0.242$, Mann-Whitney test). Thus, there is a tendency to reduce the duration of the fever with azoximer bromide (Polyoxidonium). In earlier studies of this drug effectiveness (in the form of tablets and in the form of solution for intranasal use) it was possible to record a statistically significant difference in the terms of fever treatment. In double-blind placebo-controlled studies it is shown that use of azoximer bromide (Polyoxidonium, sublingual tablets) in complex therapy of children with ARVI leads to reduction of temperature normalization period from $100.99 \pm 24.91$ hours to $80.13 \pm 20.75$ hours ( $\mathrm{p}=0.00004$, MannWhitney test) [7]. Reduction of terms of fever elimination at intranasal use of azoximer bromide solution (Polyoxidonium) in treatment of children on the average for 3,62 days $(2,35 \pm 0,15$ days at inclusion of azoximer bromide in standard therapy vs $5,97 \pm 045$ days at prescription only of standard therapy) is also shown in V.P. Vavilova et al studies [3]. Meta-analysis of the clinical studies data also confirmed that the terms of normalization of body temperature at inclusion of azoximer bromide (Polyoxidonium) in therapy of children with infectious and inflammatory diseases are reduced by 1.4 (according to the model of fixed effects) - 1.92 days (according to the model of random effects) [2]. The fever was expected to last for a longer period than they eventually got when planning this study, taking into account the presented results of previous studies. The duration of the fever was taken into account when calculating the sample size. In this regard, it is possible that with more patients included or with a longer average fever period, as in previous studies, we would have obtained a statistically significant difference in the duration of the fever period when Polyoxidonium was included in therapy.

Statistically significant differences between the groups were found on day 3 of the study on the indicator "Painful (or different) appearance" ( $p=0.047$, Pearson's test $\chi 2)$ : by day 3 of therapy in the azoximer bromide group (Polyoxidonium), the symptom was absent in $59(77.63 \%)$ patients and in $49(62.03 \%)$ comparison groups. Thus, on the 3rd day of therapy this symptom was less expressed in the group taking azoximer bromide (Polyoxidonium), because the number of patients who did not have this symptom was 1.3 times higher than in the comparison group.

A trend towards a more expressed reduction of this symptom in the azoximer bromide group (Polyoxidonium) was detected on day 5 of therapy : the symptom was eliminated in $67(88.16 \%)$ patients and $66(83.54 \%)$ comparison groups (the differences are statistically insignificant, $\mathrm{p}=0.343$, Pearson's test $\chi 2$ ). The symptom was eliminated in $100 \%$ of patients in both groups on day 8 of therapy.

Thus, azoximer bromide (Polyoxidonium) in a shorter time helps to reduce the severity of some symptoms of intoxication, which confirms the statistically significant difference on the 3rd day of therapy compared to the placebo group. On the 8th day of therapy, the expected difference between the groups was not received, because the study included patients with mild ARVI, whose typical course of treatment by the 8 th day of treatment usually means that intoxication symptoms must be eliminated.

\section{Symptoms of inflammation of the nasal mucous membrane}

Statistically significant differences were found between the drugs in relation to the symptom of 'Nasal discharge' ( $p=0.036$ and $p=0.009$, Pearson's test $\chi^{2}$, Figure 2 ) on day 3 as well as day 5 of the study.
Thus, there were twice as many patients with nasal discharge as the placebo group in the azoximer bromide group (Polyoxidonium), by the 3 rd and 5th days of therapy.

More expressed dynamics of decreasing scores compared to the placebo group with regard to such symptoms as "Nasal discharge" ( $\mathrm{p}=0.019$, Pearson's test $\chi^{2}$, day 5 comparison with baseline values), "nasal congestion/impaired nasal airflow" ( $p=0.002$, Pearson's test $\chi^{2}$, day 5 comparison with baseline values) (Figures 3 and 5) were observed in the group of azoximer bromide (Polyoxidonium). At the baseline stage, the majority of patients in both groups (76.32\% (58) in the main group and $64.56 \%$ (51) in the comparison group) had the symptom "nasal congestion/impaired nasal airflow" assessed with 2 points (moderate degree). This symptom was eliminated on the fifth day of the study in the main group in $60.53 \%$ (46) patients, with the corresponding number of patients with the eliminated symptom in the comparison group being $44.30 \%$ (35) patients (Figure 4).

\section{The total number of points according to the symptom score scale}

The total number of points on Symptom Assessment Scale decreased statistically significantly $(\mathrm{p}<0.001$, Wilcoxon criterion) in both groups on day 8 , but on day 3 there were statistically significant differences between the groups, which remained until day 5 ( $\mathrm{p}=0.049$ and $\mathrm{p}=0.017$, Mann-Whitney test, drugs comparison on days 3 and 5,

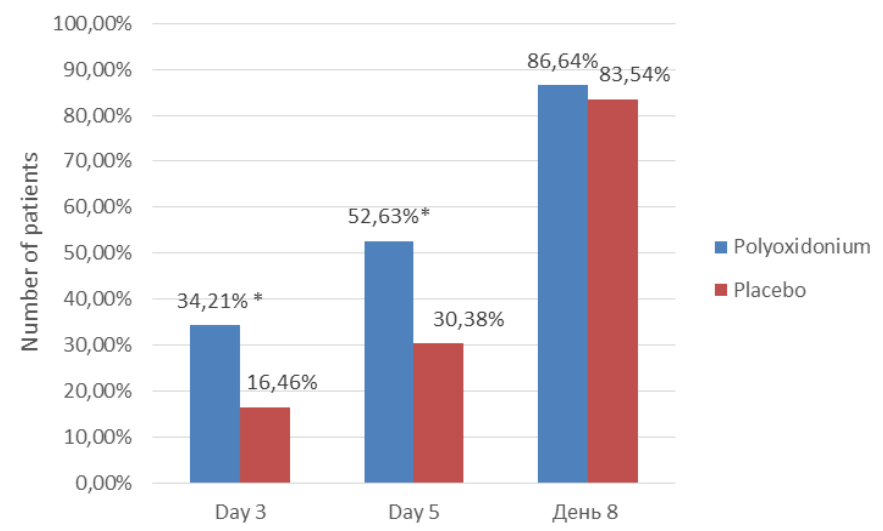

Figure 2. Dynamics of the number of patients (\%) who did not have the symptom "Nasal discharge". * the difference between groups is statistically significant $(\mathrm{p}=0.036$ on day 3 and $\mathrm{p}=0.009$ on day 5 , Pearson's test $\chi^{2}$ ).

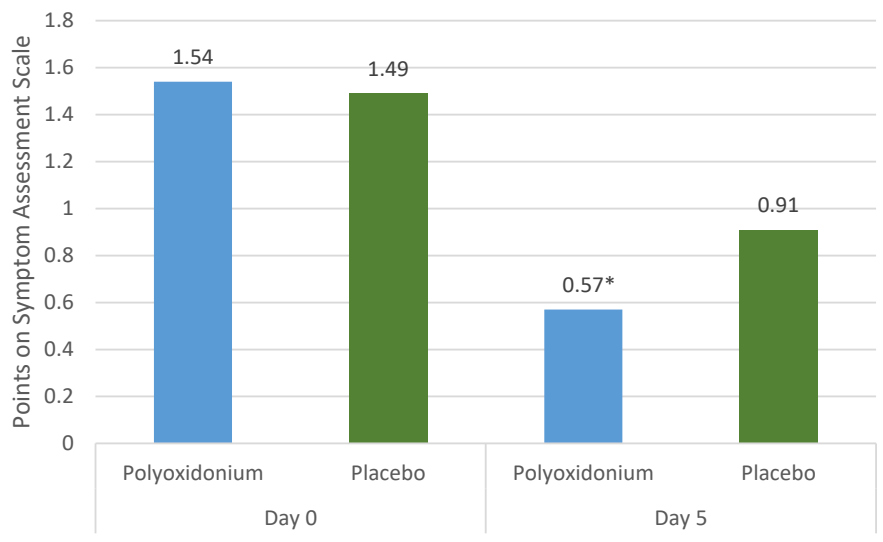

Figure 3. Dynamics of symptom severity (arithmetic mean) "Nasal discharge". * the difference between the groups of azoximer bromide (Polyoxidonium) and placebo is statistically significant $\left(\mathrm{p}=0.019\right.$, Pearson's test $\left.\chi^{2}\right)$. 


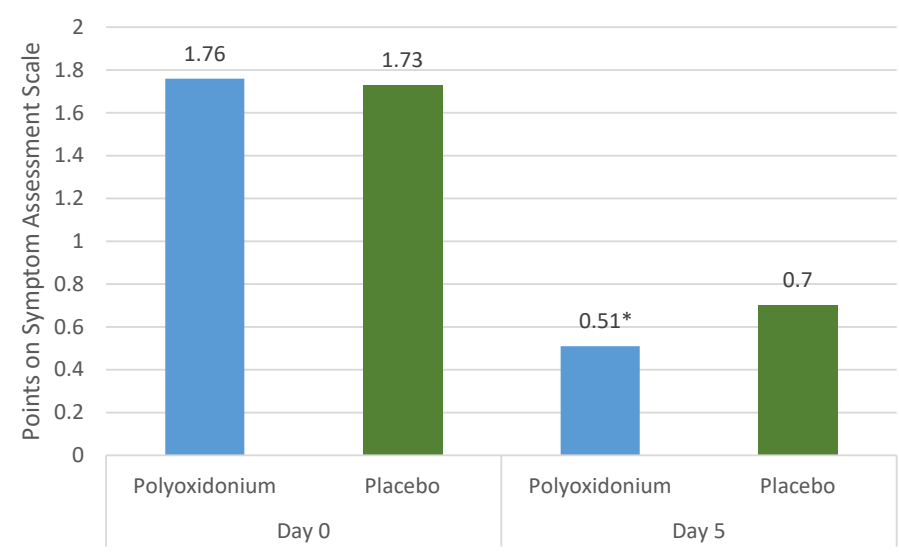

Figure 4. Dynamics of symptom severity (arithmetic mean) "Nasal discharge/impaired nasal airflow". * the difference between the groups of azoximer bromide (Polyoxidonium) and placebo is statistically significant ( $\mathrm{p}=0,002$, Pearson's test $\chi 2$ ).

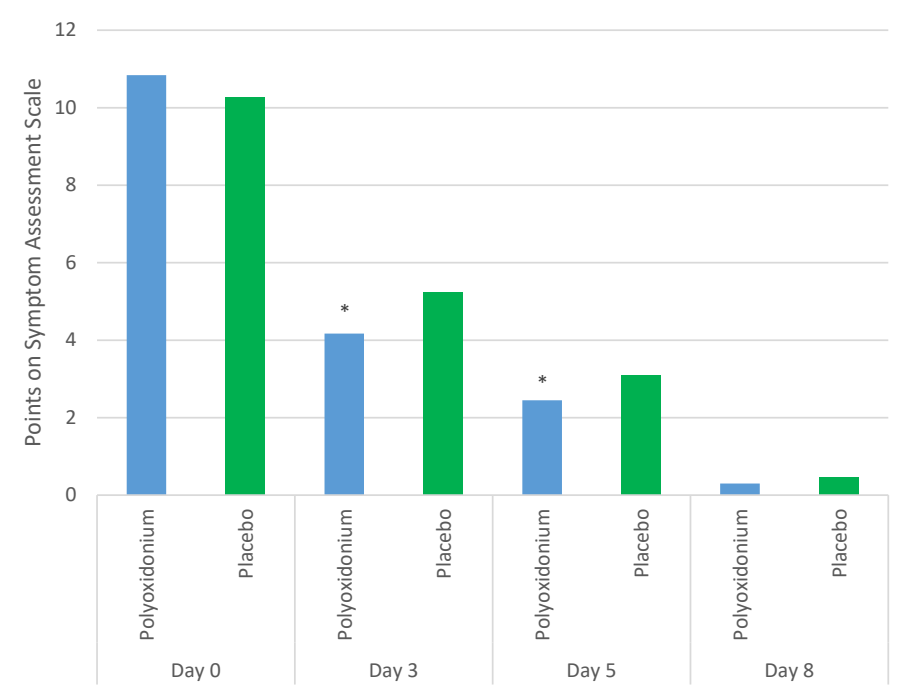

Figure 5. Dynamics of the total number of points according to the Symptom Assessment Scale. The data is presented as an arithmetic mean. ${ }^{*}$ The differences are statistically significant $(\mathrm{p}=0.049$ and $\mathrm{p}=0.017$, Mann-Whitney test, comparison of drugs at the $3 \mathrm{rd}$ and 5 th days of study, respectively).

respectively) (Figure 5). It should be noted that the above described statistically significant differences between the groups with regard to the nasal symptoms on the Symptom Assessment Scale are confirmed by the results of the physical examination. Respiratory system functions on day 3 , the state of the nasal passages, the nature of the discharge was normalized in $24(29.27 \%)$ patients of the main group and only in 3 (3.49\%) of the placebo group (the differences are statistically significant: $\mathrm{p}<0.001$, Pearson criterion $\chi 2$ ).

Thus, due to the inclusion of azoximer bromide (Polyoxidonium) in the standard ARVI treatment regimen in children, a milder course of the disease was observed, which is confirmed by a statistically significant decrease in the general evaluation of symptoms on the 3rd and 5th days of the disease in comparison with placebo group, as well as a significantly lower evaluation of the symptoms of "nasal discharge" and "nasal congestion" in the Polyoxidonium group in comparison with placebo. These effects indicate a faster solution of inflammation with topical use of the Polyoxidonium, which can be explained by the immunomodulatory, anti-inflammatory and detoxicant properties of the drug, as well as the ability to inhibit the formation of neutrophil extracellular traps. Accordingly, a reduction in the symptoms severity significantly improves a child's quality of life during the disease.

\section{Safety of studied therapy}

The number of patients exposed to the drug was 170 (84 in the group of the studied drug and 86 in the comparison drug group).

1 adverse event (AE): acute catarrhal left otitis media was reported after taking azoximer bromide (Polyoxidonium). The connection to the drug is assessed as possible.

$6 \mathrm{AE}$ were registered after taking the placebo: acute left purulent otitis - 1, Loose stool after diet disturbance - 1, acute otitis media - 1 , nasal bleeding - 1, bronchitis - 1, liquid stool - 1 .

The connection with the placebo is assessed as possible in 3 cases, doubtful - in 2 cases, conditional - in 1 case.

$4 \mathrm{AE}$ were moderate: acute purulent otitis on the left, acute otitis media, bronchitis, acute left catarrhal otitis media. The other AE were mild. All AE resolved with a full recovery. No serious adverse events have been reported.

The drug tolerance was good. The AE frequency, the frequency of complaints in the group of azoximer bromide (Polyoxidonium) did not statistically differ from the corresponding values in the placebo group. Thus, the conducted study allows us to state the safety of the studied drug Polyoxidonium.

\section{Conclusions}

Inclusion of azoximer bromide (Polyoxidonium) as a pathogenetic therapy drug in the complex treatment of children with acute respiratory infections provides an opportunity:

1. To better control the symptoms of intoxication,

2. To relieve the nasal symptoms of ARVI:

- Reduce the severity of the symptoms of "nasal discharge" and "nasal congestion" by day 5 of therapy (compared to placebo);

- Double the number of patients with nasal discharge by day 3 and 5 of therapy (compared to placebo).

3. To reduce the severity of the course of the infectious and inflammatory process, which is confirmed by the patients data, as well as lower overall scores on the Symptom Assessment Scale in patients of the group of azoximer bromide (Polyoxidonium) on the 3rd and 5th days of the disease in comparison with the placebo group.

So, topical use of azoximer bromide (as Polyoxidonium) in complex treatment of ARVI in children from 1 to 12 years is clinically effective and safe.

\section{References}

1. Bogomilsky MR, Chistyakova VR (2001) Children's otorhinolaryngology. M: GEOTAR-Media.

2. Karaulov AV, Gorelov AV (2019) The use of azoximer bromide in therapy of infectious and inflammatory diseases of respiratory system in children: meta-analysis of controlled clinical trials. J Infectology 11: 31-41.

3. Vavilova VP, Vavilov AM, Cherkaeva AH (2015) Possibilities of modern therapy of acute respiratory viral infections in children // Consilium Medicum. Pediatrics 3: $76-81$.

4. Pinegin BV (2019) Effect of azoximer bromide on formation of the extracellular neutrophil traps $R M J$ 1: 42-46.

5. Val S, Poley M, Brown K, Choi R, Jeong S, Colberg-Poley A, et al. (2016) Proteomic Characterization of Middle Ear Fluid Confirms Neutrophil Extracellular Traps as a Predominant Innate Immune Response in Chronic Otitis Media. PLoS ONE 11: e0152865. [Crossref] 
Garashchenko TI (2020) Efficacy and safety of azoximer bromide (Polyoxidonium) in children aged from 1 to 12 years with ARI: The results of a multicenter prospective, randomized, double-blind, placebo-controlled, parallel-group study

6. Toussaint M, Jackson DJ, Swieboda D, Guedán A, Tsourouktsoglou TD, et al. (2017) Host DNA released by NETosis promotes rhinovirus-induced type-2 allergic asthma exacerbation. Nat Med 23: 681-669. [Crossref]
7. Kharit SM, Galustyan AN (2017) Azoximer bromide is a safe and effective drug in the treatment of acute respiratory infections of the upper respiratory tract in children: review of the results of double blind placebo-controlled randomized clinical trials of II and III phases. Pediatrics 2: 55-61.

Copyright: $(02020$ Garashchenko TI. This is an open-access article distributed under the terms of the Creative Commons Attribution License, which permits unrestricted use, distribution, and reproduction in any medium, provided the original author and source are credited. 